\title{
PRODUÇÃO E CARACTERIZAÇÃO DE FRUTOS DE BANANEIRA 'PRATA-ANÃ'E 'PRATA-ZULU'1
}

\author{
ERVAL RAFAEL DAMATTO JÚNIOR ${ }^{2}$, ANDRÉ JOSÉ DE CAMPOS ${ }^{3}$, LUCIANA MANOEL ${ }^{4}$, \\ GLÁUCIA CRISTINA MOREIRA ${ }^{5}$, SARITA LEONEL ${ }^{6}$, REGINA MARTA EVANGELISTA ${ }^{7}$
}

\begin{abstract}
RESUMO - O trabalho objetivou comparar o ciclo cultural e a produção, além de avaliar atributos físico-químicos e sensoriais de frutos de bananeiras das cultivares Prata-Anã e Prata-Zulu, nas condições de Botucatu-SP. Foram avaliadas as seguintes características em campo: número de dias entre o plantio e o florescimento; número de dias entre o florescimento e a colheita; ciclo; peso do cacho; número de frutos por cacho; número de pencas por cacho; peso, número de frutos, comprimento e diâmetro dos frutos da $2^{\mathrm{a}}$ penca. As análises físico-químicas foram realizadas no dia da colheita e a cada 3 dias, num período de 12 dias, sendo determinados: perda de massa, firmeza, relação polpa/casca, $\mathrm{pH}$, acidez total titulável, e sólidos solúveis totais. Na análise sensorial, avaliou-se a aceitação dos atributos sabor, textura, aparência, aroma e apreciação geral dos frutos. Com os resultados obtidos, verificou-se que a cultivar Prata-Zulu apresentou produção bastante superior à 'Prata-Anã', o que indica ser uma cultivar com boas características agronômicas. Apesar de a cultivar Prata-Zulu apresentar maior perda de massa e menor firmeza, apresentou como vantagem frutos mais doces (maior SST); mesmo assim, a preferência do consumidor é pela 'Prata-Anã', que apresenta como principal vantagem as dimensões do fruto, que são menores, tornando-se assim mais práticos para o consumo.
\end{abstract}

Termos para indexação: Musa sp., 'Prata-Anã', 'Prata-Zulu', produção, armazenamento.

\section{PRODUCTION AND CHARACTERIZATION OF 'PRATA ANÃ'AND 'PRATA ZULU' BANANA FRUITS}

\begin{abstract}
This work aimed to compare the cultural cycle, production and evaluate physic chemistry and sensorial characteristics of banana fruits Prata Anã and Prata Zulu cultivars, produced in Botucatu-SP. It was evaluated the following field characteristics: days between planting and blooming; days between blooming and harvest, cycle; bunch weight; number of fruits in the bunch; number of hands in the bunch; weight, number of fruits, fruits length; and fruits diameter in the $2^{\text {nd }}$ hand. The physics chemistry analyses were realized in the harvest day and every 3 days, during 12 days, being analised: weight loss, firmness, pulp peel relation, $\mathrm{pH}$, acidity, and total soluble solids. The sensorial analyses evaluated the acceptance of flavor, firmness, appearance, smell and general appreciation of the fruits. The obtained data showed that cv. Prata Zulu had a superior production compared with 'Prata Anã'. Even though cv. Prata Zulu showed a bigger weight loss and fruits with less firmness, this cultivar had the advantage of produce sweeter fruits (bigger SST), even so the consumer prefers 'Prata Anã', that produces fruits with small dimensions as the consumer is habituated.
\end{abstract}

Index terms: Musa sp., 'Prata Anã', 'Prata Zulu', production, storage.

\section{INTRODUÇÃo}

O Brasil tem mais de 500 mil hectares plantados com banana e uma produção anual em torno de seis milhões de toneladas, sendo que quase a totalidade da produção se destina ao mercado interno. Uma das maiores preocupações dos pesquisadores em bananicultura são altas produções, com frutos de qualidade, além de evitar causar danos ao ambiente, uma vez que a cultura tem grande importância econômica e social. Desta forma, tornam-se importantes estudos com novas cultivares de banana, que melhor se adaptem às condições do produtor, além de apresentarem boas características agronômicas. No Brasil, a bananeira é cultivada em todos os Estados, desde a faixa litorânea até os planaltos do interior, em altitudes que variam de zero a mais de 1.000 metros, contribuindo para que o País seja o segundo maior produtor mundial (Alves, 1999). O Estado de São Paulo, considerando-se a safra de 1999, participa com pouco mais de $17 \%$ da produção total do País, numa área de 52 mil hectares, com uma produtividade média de 22,7 t/ha (Agrianual, 2001).

A bananeira-'Prata-Anã', também conhecida por 'Enxerto' ou 'Prata-de-Santa-Catarina' é uma planta bastante vigorosa, o que dispensa seu escoramento. Apresenta porte médio a baixo (2,0 a 3,5 m), sendo seus frutos típicos do subgrupo Prata. Essa cultivar é tolerante ao frio e mediamente tolerante a nematóides, além de apresentar bom potencial de produtividade sob condições de irrigação, podendo atingir 30-35 t/ha/ciclo (Silva et al., 1999). Zaffari et al. (1995) verificaram que esta cultivar apresenta grande tolerância ao dano causado pelo frio, observando baixa necrose da área foliar (3,83\%). E Lichtemberg et al. (2001) observaram que os frutos desta cultivar foram os que sofreram menores danos causados pelo frio, evidenciando que o genoma $\mathrm{B}$ deste grupo $(\mathrm{AAB})$ conferiu maior resistência dos frutos às baixas temperaturas.

A cultivar Prata-Zulu, originária da África, possui porte alto, ciclo vegetativo de 401 dias, na região Amazônica, possui perfilhamento bom, o pseudocaule e as folhas apresentam mais cera que as cultivares do subgrupo Prata, seus cachos pesam entre 20 e $25 \mathrm{~kg}$, com mais de 10 pencas, tem alta capacidade produtiva, tendo como produtividade esperada 33 toneladas no primeiro ciclo e chegando a 49,9 toneladas no segundo ciclo, sendo que seus frutos apresentam o pedúnculo rígido, o que lhes confere maior resistência ao despencamento, característica esta que favorece transporte a longas distâncias. Nos testes de degustação, a cv. Prata-Zulu apresenta frutos com sabor agridoce e a polpa é acinzentada com consistência pegajosa. Outra importante característica desta cultivar é ser altamente resistente à Sigatoka-negra e à Sigatoka-amarela, principais doenças fúngicas para a cultura. No entanto, é suscetível ao moko, mal-do-Panamá, broca-do-rizoma e ao nematóide cavernícola (CNPTIA-Embrapa, 2004).

Muitas transformações ocorrem durante o amadurecimento da banana, principalmente no amido, açúcares, acidez, pH, sólidos solúveis totais e taninos (Lal et al., 1974). Nessa etapa, tem-se aumento no teor de açúcares simples, aumento de ácidos simples e orgânicos

\footnotetext{
${ }^{1}$ (Trabalho 124/2004). Recebido: 08/10/2004. Aceito para publicação: 02/09/2005.

${ }^{2}$ Eng. Agr. Doutorando em Horticultura da Faculdade de Ciências Agronômicas/UNESP. Depto. de Recursos Naturais/Solos, Cep: $18603-970$ - Botucatu-SP. Email: ervaljr@fca.unesp.br.

${ }^{3}$ Eng. Agr. Doutorando em Energia na Agricultura da FCA/UNESP.

${ }^{4}$ Eng. Agr. Doutoranda em Energia na Agricultura da FCA/UNESP.

${ }^{5}$ Eng. Agr. Mestranda em Horticultura da FCA/UNESP.

${ }^{6}$ Prof $^{\mathrm{a}}$. Dra . do Depto. de Produção Vegetal - Horticultura da FCA/UNESP.

${ }^{7}$ Prof $^{a}$. Dr ${ }^{\mathrm{a}}$. do Depto de Gestão Agroindustrial da FCA/UNESP.
} 
(predominando o ácido málico) e diminuição de compostos fenólicos, acarretando em redução na adstringência e aumento da acidez, além da liberação de substâncias voláteis, fatores responsáveis pelo aroma e sabor, que são características fundamentais para a aceitação da fruta (Soto Ballestero, 1992). A acidez em frutos de bananeira varia de $0,17 \%$ a 0,67\% (Fernandes et al., 1979; Rossignoli, 1983), o pH, de 4,2 a 4,8 (Soto Ballestero, 1992), e o teor de sólidos solúveis totais aumenta até um máximo de $27 \%$, tendo pequena diminuição quando a fruta já está muito madura (Bleinroth, 1995).

A análise sensorial de frutos de novas cultivares e híbridos de plantas deve ser realizada a fim de se verificar a aceitação dos mesmos por parte dos consumidores. Essa análise é feita mediante a utilização dos sentidos humanos, como visão, gustação, olfato, audição e sensibilidade-cutânea, sendo os atributos sensoriais (aroma, sabor, textura e cor) influenciados significativamente pela composição química e, nos frutos de bananeira, principalmente pelos ácidos, açúcares e compostos fenólicos (Soto Ballestero, 1992). Dessa forma, as sensações observadas nos alimentos são usadas para avaliar sua qualidade, aceitabilidade por parte do consumidor e nas pesquisas para o desenvolvimento de novos produtos (Teixeira et al., 1987; Moraes,1988).

Este trabalho teve como objetivo comparar o ciclo cultural e a produção, além de avaliar atributos físico-químicos durante o amadurecimento e, também, avaliar sensorialmente frutos maduros de bananeiras das cultivares Prata-Anã e Prata-Zulu, cultivados nas condições de Botucatu-SP.

\section{MATERIAL E MÉTODOS}

O cultivo das bananeiras foi conduzido no pomar experimental da Faculdade de Ciências Agronômicas - UNESP de Botucatu-SP, que apresenta as seguintes coordenadas geográficas: Latitude $22^{\circ} 51^{\prime}$ sul, Longitude $48^{\circ} 27^{\prime}$ oeste e Altitude $786 \mathrm{~m}$. O solo da área foi classificado como Nitossolo Vermelho, segundo os critérios da Embrapa (1999). A área destinada ao plantio foi arada, gradeada, seguida de calagem em área total, objetivando elevar a saturação de bases a $60 \%$ e o teor de magnésio acima de $9 \mathrm{mmol} / \mathrm{dm}^{3}$ (Raij et al., 1997), em seguida aplicouse em área total chorume de esterco bovino. Foram abertas covas com dimensões de $60 \mathrm{~cm}$ de diâmetro por $80 \mathrm{~cm}$ de profundidade, as quais foram preparadas com 7 litros de esterco de curral curtido e $300 \mathrm{~g}$ de termofosfato, e a adubação de produção foi realizada de acordo com as recomendações de Raij et al. (1997). O plantio das duas cultivares foi realizado no mês de novembro de 2002, adotando-se o espaçamento de $2,5 \mathrm{~m} \times 2,5 \mathrm{~m}$. Instalou-se na área experimental um sistema de irrigação localizada por microaspersão, utilizando-se de emissores com vazão de $40 \mathrm{~L} / \mathrm{h}$. Foram realizados os tratos culturais necessários para o bom desenvolvimento das plantas, tais como limpeza/roçagem do mato, desbaste de perfilhos, retirada de folhas velhas e adubações. Não foi necessário o controle da sigatoka-amarela, uma vez que a incidência desta doença na cv. Prata-Anã foi inferior a $20 \%$ da área foliar atacada com manchas novas e na cv. Prata-Zulu a incidência da doença não foi observada.

Utilizaram-se duas cultivares de bananeira: Prata-Anã e PrataZulu, sendo avaliadas as seguintes características em campo: número de dias entre o plantio e o florescimento; número de dias entre o florescimento e a colheita; ciclo (plantio até colheita); peso do cacho (kg); número de frutos por cacho; número de pencas por cacho; peso da $2^{\mathrm{a}}$ penca $(\mathrm{kg})$; número de frutos da $2^{\mathrm{a}}$ penca; comprimento de frutos da $2^{\mathrm{a}}$ penca $(\mathrm{cm})$, medido entre as duas extremidades com régua; diâmetro de frutos da $2^{\mathrm{a}}$ penca $(\mathrm{mm})$, medido na região central dos frutos com o uso de paquímetro digital. Para as análises laboratoriais e sensoriais foram utilizadas as segundas e terceiras pencas de 5 cachos de cada cultivar, sendo colhidos no estádio de desenvolvimento equivalente a "3/4 gordo" (36-38 mm). Os frutos foram encaminhados para o laboratório, sem serem climatizados, e permaneceram em condições ambientais, sendo realizadas no dia da colheita e a cada 3 dias, num período de 12 dias, as seguintes análises físicas e químicas: perda de massa (\%) de 6 frutos; firmeza, medida em dois pontos da região central de 2 frutos; relação polpa/casca; $\mathrm{pH}$ determinado em potenciômetro (Instituto Adolfo Lutz., 1985); acidez total titulável feita com $\mathrm{NaOH} 0,1 \mathrm{~N}$ e expressa em g ác. málico x 100g polpa ${ }^{-1}$ (I.A.L., 1985); e sólidos solúveis totais ( ${ }^{\circ}$ Brix), determinados por refratometria (I.A.L., 1985). Na análise sensorial avaliou-se a aceitação dos atributos sabor, textura, aparência, aroma e apreciação geral dos frutos, sendo que, para estas análises, se atribuiu uma escala de notas que variou de um a dez ( 1 ou $2=$ péssimo; 3 ou $4=$ ruim; 5 ou $6=$ indiferente; 7 ou $8=$ bom; 9 ou $10=$ ótimo), e cada amostra foi avaliada por 10 degustadores não treinados. As análises sensoriais foram realizadas no ponto adequado de consumo, isto é, quando a coloração da casca se apresentava totalmente amarela (classificação = 6 de acordo com Soto Ballestero, 1992) e não mais apresentavam sabor adstringente, sendo os frutos servidos na quantidade de três rodelas de cada cultivar por provador, cuja espessura era de 1,5 cm.

Para o experimento em campo e análises sensoriais, foi adotado o delineamento experimental inteiramente casualizado, com 2 tratamentos (cultivares) e 10 repetições, sendo 2 plantas úteis por parcela. E para o experimento de pós-colheita (análises laboratoriais), foi empregado delineamento fatorial $(2 \times 5)$, com 2 fatores (cultivares $\mathrm{x}$ dias de armazenamento), com 10 repetições, sendo os resultados comparados pelo teste de Tukey, a 5\% de probabilidade (Banzatto \& Kronka, 1992).

\section{RESULTADOS E DISCUSSÃO}

Com os dados obtidos no primeiro ciclo de produção das duas cultivares de bananeira, observa-se que não houve diferença quanto à duração do ciclo (Figura 1), apresentando como média geral 496 dias do plantio à colheita. Essa duração do ciclo da cultura difere dos resultados encontrados por Gomes (2004), que trabalhou com doses de potássio via fertirrigação em bananeira 'Prata-Anã' em Botucatu-SP, onde o autor relata ter produzido em 386 dias. Essas diferenças na duração do ciclo de produção podem estar relacionadas ao clima, uma vez que os trabalhos foram realizados em épocas diferentes do ano, e a cultura é extremamente sensível a baixas temperaturas, paralisando seu crescimento com temperaturas inferiores a $15^{\circ} \mathrm{C}$ (Borges et al., 2000). A temperatura durante a realização do experimento mostrou-se adequada para o desenvolvimento das bananeiras, não havendo longos períodos de temperatura abaixo da mínima para o crescimento das plantas.

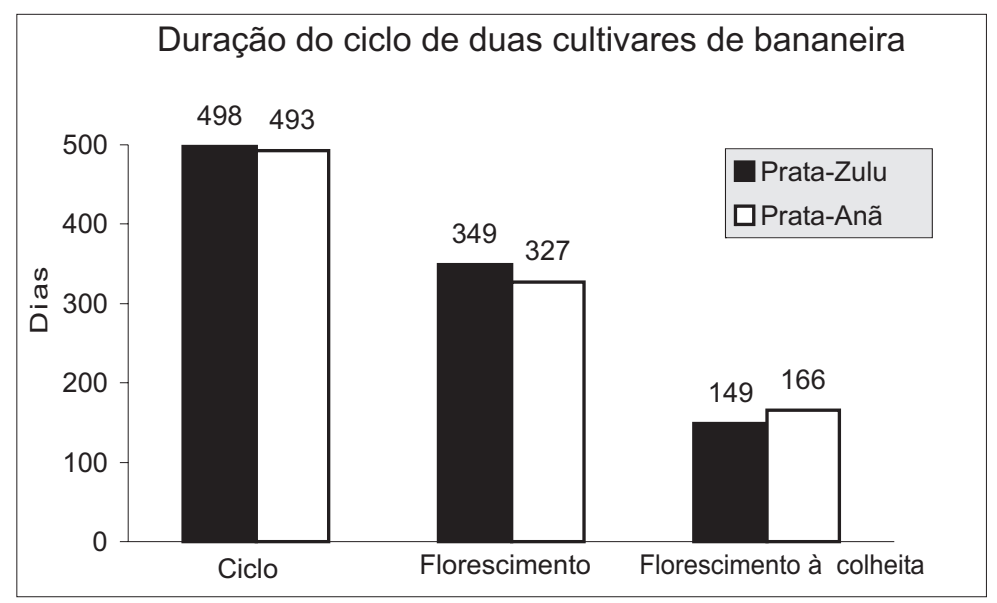

FIGURA 1 - Duração do ciclo de bananeiras 'Prata-Anã' e 'Prata-Zulu', cultivadas em Botucatu-SP (nov/2002 a nov/2003).

Mesmo não havendo diferença no ciclo de produção, encontrou-se diferença significativa no período do plantio ao florescimento entre as cultivares estudadas (Figura 1), onde a 'PrataZulu' demorou mais para florescer (349 dias) quando comparada com a 'Prata-Anã' (327 dias), porém apresentou um ciclo vegetativo mais curto que o relatado na literatura, que é de 401 dias, nas condições Amazônicas (CNPTIA-Embrapa, 2004).

Como pode ser observado na Figura 1, o período entre o 
TABELA 1 - Peso médio de cacho; número médio de frutos por cacho; número médio de pencas por cacho; número médio de frutos na $2^{\mathrm{a}}$ penca; peso médio da $2^{\mathrm{a}}$ penca e produção média de bananeiras 'Prata-Anã' e 'Prata-Zulu', cultivadas em Botucatu-SP (nov/2002 a nov/2003).

\begin{tabular}{lcccccc}
\hline Cultivar & Peso cacho (kg) & $\mathbf{N}^{\mathbf{0}}$ frutos por cacho & $\mathbf{N}^{\mathbf{0}}$ pencas por cacho & $\mathbf{N}^{\mathbf{0}}$ frutos 2 $\mathbf{p}^{\mathrm{a}}$ penca & Peso da 2 $^{\mathbf{a}}$ penca & Produção (kg/ha) $^{-}$ \\
\hline Prata-Anã & $17,70 \mathrm{~b}$ & $125,9 \mathrm{~b}$ & $9,2 \mathrm{~b}$ & $15,3 \mathrm{~b}$ & $2,01 \mathrm{~b}$ & $28,32 \mathrm{~b}$ \\
Prata-Zulu & $33,97 \mathrm{a}$ & $214,8 \mathrm{a}$ & $14,0 \mathrm{a}$ & $17,3 \mathrm{a}$ & $2,88 \mathrm{a}$ & $54,35 \mathrm{a}$ \\
\hline Médias & 25,83 & 170,4 & 11,6 & 16,3 & 2,45 & 41,34 \\
\hline CV $(\%)$ & 9,37 & 7,61 & 5,60 & 5,82 & 8,73 & 9,31 \\
\hline
\end{tabular}

Médias seguidas por letras distintas na coluna diferem pelo teste de Tukey a $5 \%$ de probabilidade.

florescimento e a colheita foi menor para a cultivar Prata-Zulu, com 149 dias, contra 166 dias da 'Prata-Anã', sendo essa diferença possivelmente causada pela época do florescimento, pois a 'Prata-Anã' floresceu em setembro e outubro, enquanto a 'Prata-Zulu' floresceu em outubro e novembro, que é um período mais quente, o que pode ter favorecido o desenvolvimento do cacho da cv. Prata-Zulu mais rapidamente. Gomes (2004) obteve 123 dias para o período que compreende o florescimento e a colheita na cultivar Prata-Anã em Botucatu-SP, podendo também essas diferenças serem explicadas através das condições climáticas diferentes, pois, em climas e períodos mais quentes, o desenvolvimento do cacho é maior. Esse menor período entre floração e colheita para a 'Prata-Zulu' observada no presente trabalho apresenta como vantagem a menor permanência dos frutos em campo; assim sendo, menores são as chances de os frutos sofrerem danos e injúrias.

A bananeira-'Prata-Zulu' apresentou cachos com peso muito superior $(33,97 \mathrm{~kg})$ à 'Prata-Anã' $(17,70 \mathrm{~kg})$ e também superior aos dados relatados para esta cultivar, que é de 20 a $25 \mathrm{~kg}$ por cacho (CNPTIAEmbrapa, 2004).

Como pode ser observado na Tabela 1 , o número de frutos por cacho apresentou diferença significativa entre as cultivares, onde a 'Prata-Zulu' produziu em média 215 frutos por cacho. A 'Prata-Anã' produziu menor número de pencas por cacho ( 9,2 pencas), quando comparada com a 'Prata-Zulu' (14 pencas). Na segunda penca, o número de frutos foi maior na 'Prata-Zulu' (17 frutos) quando comparado à 'Prata-Anã' (15 frutos), bem como o peso da segunda penca foi superior para a 'Prata-Zulu'.

Dessa forma, com os dados obtidos no experimento e apresentados na Tabela 1, a bananeira-'Prata-Zulu' apresentou o dobro da produtividade (54,35 t/ha) em comparação à 'Prata-Anã' (28,32 t/ha), sendo que era esperado para o primeiro ciclo uma produção de $33 \mathrm{t} / \mathrm{ha}$ (CNPTIA-Embrapa, 2004) para a cultivar Prata-Zulu e 30 a 35 t/ha para a 'Prata-Anã' (Silva et al., 1999). Portanto, a produção da cultivar PrataZulu foi superior aos relatos anteriores e aos esperados nas condições experimentais, enquanto a 'Prata-Anã' apresentou produtividade inferior à expectativa, possivelmente devido ao fato de a produção do primeiro ciclo da 'Prata-Anã' ser muito inferior aos demais.

Os frutos de ambas as cultivares permaneceram armazenados por um período de 12 dias no laboratório, período este onde se completou o processo de amadurecimento dos frutos, sendo que, no $12^{\circ}$ dia de armazenamento, os frutos foram descartados por não mais apresentarem condições de serem comercializados (escurecimento da casca e despencamento). No período da realização do experimento, registraramse os valores de temperatura máxima (média de $26,8^{\circ} \mathrm{C}$ ), mínima (média de $22,6^{\circ} \mathrm{C}$ ) e umidade relativa máxima (média de $60,3 \%$ ) e mínima (média de $49,0 \%$ ).

Na Tabela 2, verifica-se que a cultivar Prata-Zulu apresentou perda de massa superior à 'Prata-Anã', diferindo significativamente, possivelmente por aquela cultivar apresentar casca mais fina. Observando a Tabela 3 , verifica-se que, no decorrer dos dias de armazenamento, sob condições ambientais, a perda de massa média aumentou significativamente, passando de $4,25 \%$ ( $3^{\circ}$ dia) para $20,40 \%$ $\left(12^{\circ} \mathrm{dia}\right)$. Essa perda de massa é devida à perda de água dos frutos para o ambiente.

Com relação à firmeza dos frutos (Tabela 3), ocorreu diminuição significativa até o $6^{\circ}$ dia de armazenamento, devido ao amadurecimento dos frutos, sendo que, e a partir daí, esses valores não apresentaram queda significativa. A cultivar Prata-Anã apresentou-se mais firme em relação à Prata-Zulu.

A relação polpa/casca foi maior para a cultivar Prata-Zulu $(3,43)$, ou seja, esta cultivar apresenta maior porcentagem de polpa, diferindo da 'Prata-Anã', que apresentou esta relação inferior $(1,81)$, como pode ser observado na Tabela 2. E no período de armazenamento, houve elevação significativa para os valores médios da relação polpa/casca, sendo que, nos dois primeiros dias de avaliação, esta relação era baixa e não diferiam entre si, e com o amadurecimento dos frutos, a partir do $6^{\circ}$ dia, esta relação aumentou significativamente, mostrando que, com o amadurecimento, os frutos passam a ter maior porcentagem de polpa, uma vez que a casca perde mais água que a polpa no processo de

TABELA 2 - Valores médios de perda de massa, firmeza, relação polpa/casca, pH, acidez total titulável e teores de sólidos solúveis totais de frutos de duas cultivares de bananeiras cultivadas em Botucatu-SP (nov/2002 a nov/2003).

\begin{tabular}{ccccccc}
\hline Cultivar & Perda massa (\%) & Firmeza (gf) & Polpa/casca & pH & Acidez (g/100g) & SST ( ${ }^{\mathbf{0}}$ Brix) \\
\hline Prata-Anã & $11,13 \mathrm{~b}$ & $402 \mathrm{a}$ & $1,81 \mathrm{~b}$ & $4,85 \mathrm{a}$ & $0,32 \mathrm{a}$ & $17,23 \mathrm{~b}$ \\
Prata-Zulu & $13,04 \mathrm{a}$ & $297 \mathrm{~b}$ & $3,43 \mathrm{a}$ & $4,58 \mathrm{~b}$ & $0,29 \mathrm{a}$ & $23,25 \mathrm{a}$ \\
\hline Médias & 12,08 & 349,7 & 2,62 & 4,72 & 0,30 & 20,24 \\
\hline CV(\%) & 12,84 & 43,68 & 17,17 & 5,64 & 31,33 & 20,12 \\
\hline
\end{tabular}

Médias seguidas por letras distintas na coluna diferem pelo teste de Tukey, a $5 \%$ de probabilidade.

TABELA 3 - Valores médios de perda de massa, firmeza, relação polpa/casca, pH, acidez total titulável e teores de sólidos solúveis totais durante o amadurecimento de frutos de duas cultivares de bananeiras cultivadas em Botucatu-SP (nov/2002 a nov/2003).

\begin{tabular}{|c|c|c|c|c|c|c|}
\hline Dias de armazenamento & Perda massa (\%) & Firmeza (gf) & Polpa/casca & $\mathrm{pH}$ & Acidez (g/100g) & SST ( ${ }^{0}$ Brix) \\
\hline 0 & - & $905 \mathrm{a}$ & $1,56 \mathrm{~d}$ & $5,53 \mathrm{a}$ & $0,11 \mathrm{c}$ & $5,08 \mathrm{c}$ \\
\hline $3^{\circ}$ & $4,25 \mathrm{~d}$ & $571 \mathrm{~b}$ & $1,70 \mathrm{~d}$ & $4,78 \mathrm{~b}$ & $0,27 \mathrm{~b}$ & $13,98 \mathrm{~b}$ \\
\hline $6^{\circ}$ & $9,05 \mathrm{c}$ & $161 \mathrm{c}$ & $2,38 \mathrm{c}$ & $4,29 \mathrm{~d}$ & $0,42 \mathrm{a}$ & $25,21 \mathrm{a}$ \\
\hline $9^{\circ}$ & $14,63 \mathrm{~b}$ & $61 \mathrm{c}$ & $3,16 \mathrm{~b}$ & $4,38 \mathrm{~cd}$ & $0,41 \mathrm{a}$ & $28,64 \mathrm{a}$ \\
\hline $12^{\circ}$ & $20,40 \mathrm{a}$ & $51 \mathrm{c}$ & $4,31 \mathrm{a}$ & $4,59 \mathrm{bc}$ & $0,32 \mathrm{~b}$ & $28,90 \mathrm{a}$ \\
\hline Médias & 12,08 & 349,7 & 2,62 & 4,72 & 0,30 & 20,24 \\
\hline $\mathrm{CV}(\%)$ & 12,84 & 43,68 & 17,17 & 5,64 & 31,33 & 20,12 \\
\hline
\end{tabular}

Médias seguidas por letras distintas na coluna diferem pelo teste de Tukey, a 5\% de probabilidade. 
TABELA 4 - Sabor, textura, aparência, aroma, apreciação geral, comprimento (cm) e diâmetro (mm) de frutos de bananeira-'Prata-Anã' e 'Prata-Zulu', cultivadas em Botucatu-SP (nov/2002 a nov/2003).

\begin{tabular}{|c|c|c|c|c|c|c|c|}
\hline Cultivar & Sabor & Textura & Aparência & Aroma & Geral & Comprimento & Diâmetro \\
\hline Prata-Anã & $7,88 \mathrm{a}$ & $8,08 \mathrm{a}$ & $7,65 \mathrm{a}$ & $7,60 \mathrm{a}$ & 7,94 a & $13,38 \mathrm{~b}$ & $36,72 \mathrm{~b}$ \\
\hline Prata-Zulu & $7,27 \mathrm{a}$ & $7,56 \mathrm{a}$ & $7,90 \mathrm{a}$ & 7,52 a & $7,80 \mathrm{a}$ & $14,26 \mathrm{a}$ & $39,11 \mathrm{a}$ \\
\hline Médias & 7,58 & 7,82 & 7,78 & 7,56 & 7,87 & 13,82 & 37,91 \\
\hline $\mathrm{CV}(\%)$ & 11,73 & 8,77 & 11,22 & 9,49 & 7,41 & 2,95 & 4,43 \\
\hline
\end{tabular}

Médias seguidas por letras distintas na coluna diferem pelo teste de Tukey, a $5 \%$ de probabilidade.

amadurecimento, como pode ser visto na Tabela 3.

Na Tabela 3, observa-se que ocorreu decréscimo nos valores médios de $\mathrm{pH}$ até o $6^{\circ}$ dia, em seguida ocorreu aumento nestes valores até o $12^{\circ}$ dia de armazenamento. Sendo que a cultivar Prata-Anã apresentou valores significativamente superiores à 'Prata-Zulu' (Tabela 2). Ocorreu aumento nos valores de acidez total titulável até o $6^{\circ}$ dia, sendo que, a partir do $9^{\circ}$ dia, ocorreu decréscimo nos valores (Tabela 3 ). Não correu diferença significativa entre as 2 cultivares para os valores de acidez total titulável (Tabela 2).

A cultivar Prata-Zulu apresentou maiores valores de sólidos solúveis totais (SST), diferindo estatisticamente da cultivar Prata-Anã. Para os teores médios de SST, ocorreu aumento durante todo o período, atingindo o pico de $28,9^{\circ}$ Brix no $12^{\circ}$ dia (Tabela 3 ). Esse maior teor de SST para a 'Prata-Zulu' indica que esta cultivar apresenta frutos mais doces.

Para os resultados da análise sensorial (Tabela 4), não ocorreu diferença significativa $(\mathrm{p}>0,05)$ entre os valores obtidos pelas cultivares em relação a todos os atributos avaliados (sabor, textura, aparência, aroma e apreciação geral). Os valores médios das notas para todos os atributos ficaram em torno de 7,0, demonstrando que houve aceitação sensorial satisfatória por parte dos provadores. A maior parte dos avaliadores demonstrou maior preferência pela cultivar Prata-Anã, que apresenta sabor típico de 'Prata', ao qual o consumidor já está habituado, sendo este o possível fator de decisão da preferência.

\section{CONCLUSÕES}

A cultivar Prata-Zulu apresentou produção bastante superior à 'Prata-Anã', o que indica ser uma cultivar com boas características agronômicas, pois, além de ser mais produtiva, apresenta a vantagem de ser mais tolerante à sigatoka-amarela e principalmente à sigatokanegra, porém é suscetível à fusariose. Apesar de a cultivar Prata-Zulu apresentar maior perda de massa e menor firmeza, apresentou como vantagem frutos mais doces (maior SST); mesmo assim, a preferência, nos testes sensoriais, foi pela 'Prata-Anã', que apresenta sabor típico de 'Prata'.

\section{REFERÊNCIAS}

AGRIANUAL 2001: anuário estatístico da agricultura brasileira. São Paulo: FNP Consultoria \& Comércio, 2001.492p.

ALVES, E.J. A cultura da banana: aspectos técnicos, socioeconômicos e agroindustriais. 2.ed. rev. Brasília: Embrapa-SPI / Cruz das Almas: Embrapa-CNPMF, 1999. 585p.

BANZATTO, D.A.; KRONKA, S.N. Experimentação agrícola. Jaboticabal: FUNEP, 1992. 247p.

BLEINROTH, E.W. Matéria-Prima. In: ITAL. Banana: matéria-prima, processamento e aspectos econômicos. 2.ed. Campinas: ITAL,1995. p.133-196.
BORGES, A.L.; SOUZA, L. da S.; ALVES, E.J. Exigências edafoclimáticas. In: CORDEIRO, Z.J.M. Banana: produção aspectos técnicos. Brasília: Embrapa Comunicação para Transferência de Tecnologia, 2000. p.17-23. (Frutas do Brasil, 1).

CNPTIA-EMBRAPA. Sistemas de produção. Disponível em: $<$ http:// sistemasdeproducao. cnptia.embrapa.br/FontesHTML/Banana/ BananaAmazonas/cultivares.htm>. Acesso em: 13 jul. 2004.

EMBRAPA. Centro Nacional de Pesquisa de Solos. Sistema brasileiro de classificação de solos. Rio de Janeiro: EMBRAPA/SOLOS, 1999. $412 p$.

FERNANDES, K.M.; CARVALHO, V.D. de; CAL-VIDAL, J. Physical changes during ripening of silver bananas. Journal of Food Science, Chicago, v.44, n.4, p.1254-1255, 1979.

GOMES, E.M. Crescimento e produção de bananeiras 'prata-anã' e 'maçã' fertirrigadas com potássio. 2003. 76f. Tese (Doutorado em Agronomia / Irrigação e Drenagem)- Faculdade de Ciências Agronômicas, Universidade Estadual Paulista, Botucatu, 2004.

INSTITUTO ADOLFO LUTZ. Normas analíticas: métodos químicos e físicos para a análise de alimentos. 2.ed. São Paulo, 1985. v.1, $371 \mathrm{p}$.

LAL, R.K.; GARG, M.; KRISHNAN, P. S. Biochemical aspects of the developing and ripening banana. Phytochemistry, New York, v.13, n.11, p.2365-2370, 1974.

LICHTEMBERG, L.A.; MALBURG, J.L.; HINZ, R.H. Suscetibilidade varietal de frutos de bananeira ao frio. Revista Brasileira de Fruticultura, Jaboticabal, v.23, n.3, p.568-572, 2001.

MORAES, M. A. C. Métodos para a avaliação sensorial dos alimentos. 7.ed. Campinas: Unicamp, 1988.93p.

RAIJ, B. van; CANTARELLA, H.; QUAGGIO, J.A.; FURLANI, A.M.C. (Ed). Recomendações de adubação e calagem para o Estado de São Paulo. 2.ed. rev. e atual. Campinas: Instituto Agronômico/Fundação IAC, 1997.285p. (Boletim Técnico, 100).

ROSSIGNOLI, P. A. Atmosfera modificada por filmes de polietileno de baixa densidade com diferentes espessuras para conservação de bananas 'Prata' em condições ambiente. 1983. 80f. Dissertação (Mestrado em Fisiologia) - Escola Superior de Agricultura de Lavras, Lavras, 1983.

SILVA, S. de O. e; ALVES, E.J.; SHEPHERD, K.; DANTAS, J.L.L. Cultivares. In: ALVES, E.J. A cultura da banana: aspectos técnicos, socioeconômicos e agroindustriais. 2.ed. Brasília: Embrapa-SPI / Cruz das Almas: Embrapa-CNPMF, 1999. p.85-106.

SOTO BALLESTERO, M. Banano: cultivo y comercialización. 2.ed. San José: Litografia e Imprenta LIL, 1992. 674p.

TEIXEIRA, E.; MEINERT, E. M.; BARBETTA, P. A. Análise sensorial de alimentos. Florianópolis: UFSC, 1987. 180p. (Série Didática).

ZAFFARI, G.R.; LICHTEMBERG, L.A.; STUKER, H. Grau de susceptibilidade ao frio de cultivares de bananeira em Santa Catarina. Revista Brasileira de Fruticultura, Cruz das Almas, v.17, n.3, p.69$75,1995$. 